\title{
Assessment of the Connection of Antisocial-Criminal Behavior, Corruption and Depression in College Students
}

\author{
Iris Xóchitl Galicia Moyeda, Alejandra Sánchez Velasco, Francisco Javier Robles Ojeda \\ Universidad Nacional Autónoma de México, Iztacala, Mexico
}

\begin{abstract}
Youth is exposed to several risks that make them prone to antisocial and criminal behavior. Depression is present in a significant percentage of young adults, and since depression features a lack of emotional self-regulation, there is a possibility to establish some connections between depressive levels, criminal behavior and corruption. In this study, those connections were assessed in 73 psychology students, oscillating from 19 to 22 years old. When applied, the Antisocial-criminal AC Behavior Test, the Zung Depression Test and the Corruption Questionnaire revealed that that subjects experiencing depression show greater scores in antisocial behavior. Furthermore, the depression variable scores were significantly correlated only with antisocial behaviorand criminal as well as in corruption. Nevertheless, significant differences in both groups were only found in antisocial behavior. The relationship suggests that the link between them can be explained by similar functioning of the regulating mechanisms leading to the lack of inhibitory behavior.
\end{abstract}

Keywords: college students, antisocial-criminal behavior, depression, gender, inhibitory behavior

\section{Introduction}

Adolescents and young adults are exposed to different conditions that make them more likely to develop socially undesirable behavior. Some authors consider this behavior as antisocial and draw a distinction among them. Burt (2012) describes two differentiated components in antisocial behavior: on one hand, physically aggressive behavior, and on the other hand, rule breaking. Physically aggressive behavior is also known as manifest antisocial behavior, and it is defined as performing acts of physical aggression (i.e., hitting, pushing, slapping, biting, kicking, etc.), fights, physical violence threats, disagreements, defying attitude and/or intimidation. While rule breaking is also known as covert antisocial behavior, which is defined as the display of behaviors aimed at breaking rules, and also includes damage to property, theft, vandalism, setting fire, rule breaking, truancy, escaping and substance use.

Some other authors draw the same distinction, but they use different terms to refer to it. Antisocial behavior refers to acts that clearly infringes social rules and go again the others, frequently in an aggressive and/or violent nature. As a result, a behavior is categorized as antisocial according to social judgment and value on the severity of the acts committed and on deviation from normative patterns enacted by a specific society (Andreu \& Peña, 2013). Breaking other people's belongings; hitting other; skipping school; throwing cars to

Iris Xóchitl Galicia Moyeda, Ph.D., Facultad de Estudios Superiores, Universidad Nacional Autónoma de México. Alejandra Sánchez Velasco, MSc., Facultad de Estudios Superiores, Universidad Nacional Autónoma de México. Francisco Javier Robles Ojeda, MSc., Facultad de Estudios Superiores, Universidad Nacional Autónoma de México. 
people, houses and cars; amongst others, constitute examples of this. While covert antisocial behavior, related to disrespecting laws enacted by society, is also known as criminal behavior and is defined as legal designation, based generally on the contact with laws of justice from the country where the individual is located (Kazdin \& Buela-Casal, 1996, p. 31). Theft, vandalism, pyromania and drug selling can be cited as examples.

Research has found that the physical aggression aspect has a more stable and consistent presence throughout life, unlike the rule breaking aspect, which has an inconsistent presence. Physical aggression is more frequent within the first years of life, and diminishes during adolescence. However, as mentioned above, this aspect is stable and consistent, and, consequently, most children with aggression problems continue to display that behavior through adolescence and adulthood (Burt, 2012), which makes the presence of antisocial behavior possible. With regard to the rule breaking aspect associated with criminal behavior, it has been observed that it starts to appear more frequently in adolescence and decreases in adulthood. It has been reported that rule violation is rare in children. A possible explanation to this is that the late onset of this behavior is related to the need of a higher cognitive ability to display this behavior, which will appear until adolescence.

Since criminal behavior is related to disrespecting the law and regulations established by society, it is viable to assume that it is associated with corrupt behavior, which can be defined as obtaining illicit favors in exchange for an economic profit or of other nature, generally by abuse of power, by abuse of office or by other means. According to Suárez (2005), corrupt acts can be described as violating rules, regulations (both written and unwritten) as well as habits and customs; making a clandestine exchange in order to obtain access to means of influence or decision making, to obtain benefits (personal or for other participants). For Osoba (1996), corrupt behavior is antisocial behavior that provides befits contrary to legal and moral regulations. According to these considerations, corrupt behavior could be considered as covert or criminal antisocial behavior, which entails a high cognitive level, and which has a tendency to appear in adolescence. However, there is no clear information related to the association between the tendency to display criminal and corrupt behavior especially in late adolescence and/or early adulthood, which is one of the intentions of this paper.

It is thought that antisocial acts of an individual entail different elements, including external environment surrounding family, namely, circumstances related to social environment, the way in which family interactions and individual factors are established.

Social capital models position the role of education to promote democratic values and to diminish, for example, tolerance to government corruption. It has been particularly assessed whether knowledge of civic content has an influence on corrupt behavior perception. In that regard, Carrasco, Gonzalez, Cortés, García, and Dassen (2013) assessed college students and found that permissiveness to corruption in government institutions is mainly negatively associated to civic knowledge acquired by the students, not to other variables like educational level or socioeconomic status, a negative association between civic knowledge, government authoritarianism and disobedience to law.

With regard to family environment, there is evidence supporting both that close attachment between parents and their adolescent children constitutes a good predictor variable of antisocial behavior, and that exposure to domestic violence is associated to the development of crime related behavior, so that, when a strong and positive family attachment is experienced in childhood, there is a lower risk of antisocial behavior in adolescence. Similarly, attachment seems to be linked to delinquency risk reduction (Sousa et al., 2011).

With regard to individual factors, two predictor variables of antisocial behavior related to personality have been found: a low restraint level, characterized by lack of inhibitory behavior of negative behavior, and 
neuroticism, which is defined as the likelihood to experiment aversive affective states, including anxiety and anger. Both predictor variables appear differently in physical aggression and rule breaking aspects. Physical aggression is mainly correlated to high neuroticism levels, especially with negative emotionality and unexplainable mood swings; while there is a correlation between the rule breaking aspect and low restraint, specially of impulsive behavior (Burt, 2012). Other individual aspect associated to antisocial behavior is related to the so-called executive functions, namely, to the superior cognitive processes associated with the selfregulation of cognitive, behavioral and emotional objectives. Research has shown a negative correlation between such functions and the physical aggression aspect; while a correlation with the rule breaking aspect has not been found. The difficulty to report behavior associated with rule breaking can be a possible explanation for these results, i.e., adolescents easily conceal this behavior from their parents, unlike physical aggression-related behavior.

There is not much information regarding characteristics related to corruption perception and/or approval in individuals. For example, there is no conclusive reference to the role of gender in corrupt behavior. However, some data reveals that women are less susceptible of committing corrupt acts (Seppänen \& Virtanen, 2008). As for age, testimony seems to imply that, the older the individuals are, the less involved they are in corrupt acts. Nevertheless, the cohort effects that may have an influence are not clear (Torgler, 2006). Appraisals emerging from the religion-corruption pairing, according to both studies conducted in different countries, and the assessment of different religions, show that the religion of an individual may help both to discourage and encourage corrupt behavior (Treisman, 2000; Karimu, 2014).

The role of the consideration of consequences of an individual's acts in order to decide whether he or she will get involved in corrupt acts has been researched. Those who do it are supposed to lack the ability to identify how probable the consequences are, or, when there are events operating jointly, they are prone to be conceived as independent (Djawadi \& Fahr, 2013).

On the other hand, there have been efforts to identify the psychological dispositions of individuals towards corruption. Particularly, control mechanisms have been researched. Vicuña et al. (2004) analyzed the attributional style in students, both adolescents and young adults, with the aim of identifying the dimensions of external or internal control, stability or instability, specificity or globally and importance of individuals when they are capable to face daily corruption conditions. To provide general information, it can be observed that the older an individual gets, the more attention they will pay to corrupt acts, as well as the fact that women are more prone than men to consider corruption as an important issue. Based in the combinations of the dimensions explored, the authors opted for two explanation styles: optimistic and pessimistic. When the combination is external, unstable, specificity, the person was considered to have an optimistic explanation style. In this regard, data reveals that $73 \%$ of the evaluated students correspond to the optimistic explanation style. Age, and not gender, was an important factor. The younger an individual is, the greater the externality and instability.

These studies reveal the attitudes that individuals have towards corrupt acts of governmental nature, but there is way less information available about attitudes towards corrupt acts that could happen in an individual's daily life. For example, many corrupt acts can occur within the school environment without them being recognized, because they are sometimes considered as a "bad professional conduct" (Heyneman, 2011). Particularly, there is evidence that culture of legalities not sufficiently developed in college students, evidencing that $50 \%$ of students will commit an illegal act, little as it may be (Ahumada, Gallegos, \& Robles, 2013), which would lead us to accept, tolerate and even commit corrupt acts, as it has been found that civic 
knowledge can reduce tolerance towards corruption. Furthermore, with education in culture of legality being scarce, more antisocial and criminal acts can be committed.

That being said, emotional elements could also be associated with corrupt behavior. It is known that a low behavior restriction, especially when it is impulsive, is an element, which is present in criminal behavior and under which corruption can be placed. Individuals presenting criminal behavior stand out due to the lack of inhibition of negative behavior (Burt, 2012). However, some data seems to suggest that superior cognitive processes associated to cognitive, behavioral and emotional objective self-regulation do not have a clear role in rule breaking behavior. Thus, it should be researched whether the lack of emotional self-regulation could be associated with the tendency to accept and/or perceive corrupt behavior in a subject with a developed cognitive level.

Since depression features a lack of emotional self-regulation, there is a possibility to establish some relations between depressive levels, criminal behavior and corruption. Research on college students reveals that $20 \%$ of them show different depression levels, which may imply that they have low emotional self-regulation levels. Therefore, the objective of this paper is to analyze the relationship between antisocial-criminal behavior, corruption and depression in college students.

\section{Materials and Methods}

\section{Participants}

73 first semester psychology students, 53 females and 20 males, oscillating from 19 to 22 years old, participated voluntarily and by availability.

\section{Instruments}

Antisocial-criminal AC Behavior Test (Seisdedos, 1995). It consists of 40 items divided into two scales. Scale A assesses antisocial behavior, it consists of 20 items, and alludes to behavior deviating from social rules, for example: whistling in a gathering, eating at class when it is not forbidden. The remaining items belong to Scale C, which assesses criminal behavior and considers out of law behavior, like belonging to a gang, obtaining money by threatening weaker people or buying forbidden beverages, amongst others. Each item is answered with a Yes $=1$ or a No $=0$.

Zung Depression Test. It consists of 20 items with 4 answer options, allowing to asses a person's depression level according to four levels, depending on the score obtained: normal ( 0 to 49 points), minor to mild (50 to 59 points), moderate to considerable (60 to 69 points), and severe to extreme (70 points or more).

Corruption Questionnaire. It is structured by 8 cases in which a problem situation is laid out and there are 3 options exemplifying answers that reflect a high, low or nonexistent level of honesty.

\section{Procedure}

Researchers applied the three instruments in just one session, to one group, in a classroom. Data was discretionally handled.

\section{Results}

The assessed participants report having displayed antisocial behavior at least once in their lives. Amongst the most reported antisocial behaviors are the following: eating at school or work when it is forbidden (78.1\%), arriving late to work or school (75.3\%), saying "bad words" (71.2\%), ringing someone's door and running 
away (63\%), going out without permission (61.6\%) and refusing to doing chores one has been entrusted with (57.5\%). Other reported antisocial behavior that was unusually displayed was breaking or dropping other people's belongings, littering streets and forbidden places (13.7\% each). As for criminal behavior, the most common was drug consumption (32.7\%), entering a forbidden place or purchasing forbidden beverages $(27.2 \%)$, frequently gambling more money than one is capable of spending $(8.2 \%)$, and damaging public places $(8.2 \%)$.

In reference to median answer scores, antisocial behavior had an average of 8.14 , criminal behavior 1.18 and the corruption value had an average of 8.51. Upon carrying out a difference an assessment of difference with the U Man Whitney Test, it was found that women have a lesser average range than men in these three variables, although many differences are not statistically significant (see Table 1).

Table 1

Differences by Gender in Antisocial, Criminal Behavior and Corruption Average Range

\begin{tabular}{lllll}
\hline & Average range in men & Average range in women & $z$ & $p$ \\
\hline Antisocial behavior & 39.25 & 36.15 & -0.559 & 0.576 \\
Criminal behavior & 43.75 & 34.45 & -1.769 & 0.077 \\
Corruption & 37.63 & 36.76 & -0.156 & 0.876 \\
\hline
\end{tabular}

With regards to depression levels, it was found that most participants do not experience depression (56.2\%), followed by those who experience mild depression (27.4\%), moderate depression (15.1\%), and severe depression (1.3\%). A differentiated analysis by gender revealed that a greater percentage of men not experiencing depression in comparison with women. No case of severe depression in men was detected, while in women a minimum percentage was detected (see Table 2).

Table 2

Percentage of Depression Levels in Total Sample in Men and Women

\begin{tabular}{llll}
\hline & Total sample & Women & Men \\
\cline { 2 - 4 } & $\%$ & $\%$ & $\%$ \\
\hline No depression & 56.2 & 39.7 & 16.4 \\
Mild depression & 27.4 & 19.18 & 8.22 \\
Moderate depression & 15.1 & 12.35 & 2.74 \\
Severe depression & 1.4 & 1.4 & -- \\
\hline
\end{tabular}

By dividing the sample according to their depression condition (no depression group and depression group) and by carrying out an analysis of differences with the Mann Whitney $U$ Test, it was identified that subjects experiencing depression show greater scores in antisocial and criminal behavior, as well as in corruption. Nevertheless, significant differences in both groups were only found in antisocial behavior (see Table 3 ).

Table 3

Difference in Average Range in Antisocial and Criminal Behavior and Corruption, According to Depression Condition

\begin{tabular}{lllll}
\hline & $\begin{array}{l}\text { No depression group } \\
(n=41)\end{array}$ & $\begin{array}{l}\text { Depression group } \\
(n=32)\end{array}$ & $z$ & $p$ \\
\hline Antisocial behavior & 29.76 & 46.28 & -3.314 & 0.001 \\
Criminal behavior & 33.07 & 42.03 & -1.897 & 0.058 \\
Corruption & 35.24 & 39.25 & -0.807 & 0.420 \\
\hline
\end{tabular}


As for drug consumption, it was detected that $32.9 \%$ of participants have partaken some time, so participants were divided into two groups: those who hadn't used drugs, and those who had, and a later statistic analysis was carried out with Mann Withney's $U$ to determine if there were statistically significant differences in the display of antisocial behavior. The drug consuming group had greater ranges in all analyzed variables in opposition to those who do not consume drugs. Differences in antisocial behavior, criminal behavior and corruption are statistically significant (see Table 4).

Table 4

Differences in Average Range of Antisocial and Criminal Behavior, Corruption and Depression According to Drug Consumption Status

\begin{tabular}{lllll}
\hline & Drug consuming group & Non drug consuming group & $z$ & $p$ \\
\hline Antisocial behavior & 50.77 & 30.26 & -3.896 & 0.001 \\
Criminal behavior & 53.88 & 28.73 & -5.039 & 0.001 \\
Corruption & 44.23 & 33.46 & -2.054 & 0.040 \\
Depression & 43.15 & 33.99 & -1.735 & 0.083 \\
\hline
\end{tabular}

A Spearman correlation analysis was carried out, where a significant relationship between the corruption variable as well as with the antisocial and criminal behavior data. The depression variable scores were significantly correlated only with antisocial behavior (see Table 5).

Table 5

Correlations Between Antisocial and Criminal Behavior, Corruption and Depression

\begin{tabular}{|c|c|c|c|c|c|c|c|c|}
\hline & \multicolumn{2}{|c|}{ Antisocial behavior } & \multicolumn{2}{|c|}{ Criminal behavior } & \multicolumn{2}{|c|}{ Corruption } & \multicolumn{2}{|c|}{ Depression } \\
\hline & $r$ & $p$ & $r$ & $p$ & $r$ & $p$ & $r$ & $p$ \\
\hline Antisocial behavior & --- & --- & 0.616 & 0.001 & 0.342 & 0.003 & 0.382 & 0.001 \\
\hline Criminal behavior & 0.616 & 0.001 & --- & --- & 0.270 & 0.021 & 0.192 & 0.104 \\
\hline Corruption & 0.342 & 0.003 & 0.270 & 0.021 & --- & --- & 0.017 & 0.883 \\
\hline Depression & 0.382 & 0.001 & 0.192 & 0.104 & 0.017 & 0.883 & --- & --- \\
\hline
\end{tabular}

\section{Discussion and Conclusions}

Results show that most participants have displayed antisocial or criminal behavior, although it is important to note that the scores obtained by the sample are lower than the measurement scales medium, which suggests that relatively low levels of this type of behavior were displayed. It was detected that men were more prone than women to display antisocial and criminal behavior, but these differences were statistically insignificant. As far as corruption, something similar occurs; men have higher scores but the difference compared with women is insignificant. This data somehow matches the results of some other research, where some studies report differences regarding gender and some do not (Sanabria \& Uribe, 2009; Seppänen \& Virtanen, 2008; Vicuña et al., 2004, 2006).

The small differences found could be attributed to gender roles, i.e., the idea that both genders have played different roles, and taken up different spaces in social systems and structures. In the case of men, it is socially acceptable that they be daring, engage in risky behavior and test themselves before certain social demands (Juárez et al., 1998), as well as the findings of research reporting a link between males and criminal behavior, thus reinforcing the perception of gender differences in general population, where men are more prone to be involved in criminal behavior. It should be mentioned that the aforementioned influence also presents itself in 
the scientific community and it has had some consequences; for example, a great amount of scientific production on Criminology has only revolve around male samples, thus creating a bias in the interpretation of criminal behavior in women (Steffensmeier \& Allan, 1996).

On the other hand, the absence of significance in the differences between men and women may be interpreted in light of the proposals of Simon and Adler (1975, as cited in Rodríguez, 2009), who note that, the more women engage in public life and receive similar treatment, the more criminal rates will increase. In spite of this appreciation, Rodriguez (2009) believes that the explanation of criminal behavior in women has been biased, where differences are taken for granted as being of the gender kind, but in several occasions, they are simply extrapolations made from theoretical models validated with male samples. In recent research, gender only constitutes a control variable (Lanctôt \& Le Blanc, 2002). Due to the above, in the analysis of data stemming from classic literature taking into consideration the gender variable, it is not clear whether factors affecting in rule breaking behavior in men are the same ones that influence female criminal behavior.

In this study, as others, reports the barely existent difference between men and women, but does not analyze the factors involved, which suggests a deeper study of the impact of elements that could facilitate criminal behavior in both genders. This would contribute with evidence for analyzing Rutter, Giller, and Hagell's proposal (2000), who suggest that differences in gender in antisocial and criminal behavior are mainly due to risk and protection factors to which individuals are exposed to in a greater o lesser extent, and not to the existence of radically different factors in each gender's vital path.

The relationship found between depression and antisocial and criminal behavior suggests that the link between them can be explained by similar functioning of the regulating mechanisms leading to the lack of inhibitory behavior, as suggested by Burt (2012). On the other hand, not finding any association whatsoever between depression and corruption may lead to think that no emotional aspects of the individual influence the latter, a piece of information that can be confirmed in other studies. There is evidence of the existence of a variety of instances of behavior associated to corruption; for example, Sced (2004), upon reviewing several studies, suggests that certain personality elements in corrupt individuals, detected by several tests, differ significantly from those in non-corrupt individuals. In their turn, Kumolohadi and Budiharto (2014) refer to the existence of personality factors that could be identified to be against corruption, nine of which have been included in a test called Anticorruption Personality Scale. These studies, along with others, suggest that aspects taken into consideration in personality tests have a deeper association with corruption than they are to depression. On the other hand, Vicuña et al. $(2004 ; 2006)$ have suggested that individuals with a pessimistic attributional style have a psychological disposition for corruption. Therefore, even if corruption can be identified as criminal behavior, the influence that different mechanism have on it should also be taken into account.

The fact that the information presented in this report may be due both to the age and education level of participants should not be forgotten, as it has been mentioned that, the higher the education level and the older the individuals are, the lower the presence of corrupt actions and tolerance towards them will be (Torgler, 2006), and this, together with the evidence of depression being lower at the ages of the participants, might explain the scarce influence that depressive states have on the perception and acceptance of criminal behavior, and in this case, corrupt behavior. Therefore, other studies where the aforementioned relationship in individuals of different ages, as well as education and depression levels should be carried out.

The type of situation in which corrupt behavior should present itself is also an aspect that should be taken into consideration. Several scales assessing attitudes towards such behavior usually include items related to 
social character conditions, without completely involving individuals. An example of such items is the following: A good government may reduce corruption (Gbadamosi \& Bello, 2009). In contrast, the items in this study referred more to personal behavior.

Regarding this, a inquiry into the existence of a relationship between attitudes shown by a same individual facing several corrupt situations is suggested. As the sample in this research particularly consisted of college students, it would be interesting to know both their experiences and attitudes towards corrupt acts within the academic environment and that are not considered as such, but as bad academic behavior (Heyneman, 2011). Analyzing whether this attitude has a link with attitudes towards other types of criminal behavior and whether one of them is associated with depression level in individuals.

\section{References}

Ahumada, O., Gallegos, V., \& Robles, N. (2013). Arraigo de la cultura de la legalidad en los alumnos de la Facultad de Contaduría y Administración de la Universidad Autónoma de Chihuahua. Conference paper submitted for the XVI Congreso Internacional sobre Innovaciones en Docencia e Investigación en Ciencias Económico Administrativas, September 11-13, 2013, Mazatlán, Sinaloa. Retrieved from http://www.fca.uach.mx/apcam/2014/04/04/Ponencia\%2075-UACH.pdf

Andreu, J. M., \& Peña, M. E. (2013). Propiedades psicométricas de la Escala de Conducta Antisocial y Delictiva en adolescentes. Anales de Psicología, 29(2), 516-522.

Burt, S. A. (2012). How do we optimally conceptualize the heterogeneity within antisocial behavior? An argument for aggressive versus non-aggressive behavioral dimensions. Clinical Psychology Review, 32(4), 263-279.

Carrasco, D., Gonzalez, R., Cortés, F., García, L., \& Dassen, N. (2013). Civic knowledge and student attitudes towards corruption: The Chilean case, a multilevel path analysis approach. Conference paper submitted for the 5th IEA International Research Conference, June 26-28, 2013, Singapore.

Djawadi, B., \& Fahr, R. (2013). The impact of risk perception and risk attitudes on corrupt behavior: Evidence from a petty corruption experiment. Discussion Paper Series No. 7383, retrieved from http://poseidon01.ssrn.com/delivery.php?ID=3110710730290701060851100130891201200030550260270310231010340270 0302704700312312703009908609003007908409111812609512609211601810700102612502509710008800208402301408 9066083094095\&EXT=pdf

Gbadamosi, G., \& Bello, M. (2009). The King's new clothes in the eyes of the beholder: Developing a measurement scale for attitude towards corruption. In E. Kaynak, \& T. D. Harcar (Eds.), Management challenges in an environment of increasing regional and global concerns. Proceedings of the 18th World Business Congress (IMDA), July 1-5, Tbilisi, Georgia, pp. 73-78. Retrieved from http://eprints.worc.ac.uk/664/1/WRaP_Attitude_towards_corruption_-_Gbadamosi\%2C_G.\%26_Bello\% 2C_M._IMDA_2009.pdf

Heyneman, S. (2011). The concern with corruption in higher education. In T. Bertram (Ed.), Creating the ethical academy: A systems approach to understanding misconduct and empowering change in higher education (pp. 13-26). Routledge: New York.

Juárez, F., Medina-Mora, E., Berenzo, S., Villatoro, J. A., Carreño, S., López, E. K., Galván, J., \& Rojas, E. (1998). Antisocial behavior: Its relation to selected sociodemographic variables and alcohol and drug use among Mexican students. Substance Use and Misuse, 33(7), 1437-1459.

Juárez, G. F., Villatoro, V. J., Gutiérrez, L. Ma., Fleiz, B. M., \& Medina-Mora, E. (2005). Tendencias de la conducta antisocial en estudiantes del Distrito Federal: Mediciones 1997-2003. Salud Mental, 28(3), 60-68.

Karimu, O. (2014). University students perceptions and attitudes of corruption in Nigeria (Dissertation Presented in Partial Fulfillment of the Requirements for the Degree Doctor of Philosophy, Capella University). Retrieved from http://gradworks.umi.com/36/33/3633461.html

Kazdin, A. E., \& Buela-Casal, G. (1996). Conducta antisocial evaluación, tratamiento y prevención en la infancia y adolescencia. Madrid: Ediciones Pirámide.

Kumolohadi, R., \& Budiharto, S. (2014). Strengthning anti-corruption carácter on leader through prophetic training and counseling. International Journal of Social and Human Behaviour Study, 1(2), 5-9.

Lanctôt, N., \& Le Blanc, M. (2002). Explaining deviance by adolescent females. In M. Tonry (Comp.), Crime and justice (pp. 113-202). Chicago: University of Chicago. 
Osoba, J. A. (1996). Corruption in Nigeria: Historical perspectives. Review of African Political Economy, 69(23), $371-386$. Retrieved from http://www.roape.org/pdf/6903.pdf

Rodríguez, J. (2009). Criminología y género: Comentarios a partir del gender gap. Capítulo Criminológico, 37(4), 161-182.

Rutter, M., Giller, H., \& Hagell, A. (2000). La conducta antisocial de los jóvenes. Madrid: Cambridge University Press.

Sanabria, A. Ma ., \& Uribe, R. A. (2009). Conductas antisociales y delictivas en adolescentes infractores. Pensamiento Psicológico, 6(13), 203-218.

Sced, M. (2004). Screening for corruption using standard psychological tests of personality: A review of research evidence. Australasian Centre for Policing Research.

Seisdedos, N. (1995). Cuestionario A-D: Conductas Antisociales y Delictivas. Madrid: TEA ediciones.

Seppänen, M., \& Virtanen, P. (2008). Corruption, poverty and gender: With case studies of Nicaragua and Tanzania. Helsinki, Finland: Ministry for Foreign Affairs, Development Policy Information Unit.

Sousa, C., Herrenkohl, T., Moylan, C. A., Tajima, E., Kilka, J., Herrenkohl, R., \& Russo, M. (2011). Longitudinal study on the effects of child abuse and children's exposure to domestic violence, parent-child attachments, and antisocial behavior in adolescence. Journal Interpersonal Violence, 26(1), 111-136.

Steffensmeier, D., \& Allan, E. A. (1996). Gender and crime: Toward a gendered theory of female offending. Annual Review of Sociology, 22, 459-487.

Suárez, J. C. (2005). Una aproximación a la lucha contra la corrupción. Tercer Congreso Argentino de Administración pública. San Miguel de Tucumán, Argentina.

Torgler, B. (2006). Corruption and age. Journal of Bioeconomics, 8, 133-145.

Treisman, D. (2000). The causes of corruption: A cross-national survey. Journal of Public Economics, 78(3), 399-457. Retrieved from http://dx.doi.org.library.capella.edu

Vicuña, L., Hernández, H., Paredes, M., Rivera, J., Ríos, J., Santillana, C., \& Torres, J. (2006). Percepción, tipos y medidas de control de la corrupción, según el sexo, ciclo académico y la facultad a la que pertenecen los estudiantes universitarios. Revista de Investigación en Psicología, 9(2), 65-91.

Vicuña, L., Hernández, H., Ríos, J., Vargas, Q., Santillana, C., Sarmiento, E., Jiménez, A., Palomino, D., Retamozo, N., Munguía, M., \& Torres, M. (2004). Disposiciones psicológicas hacia la corrupción en escolares y universitarios de la ciudad de Lima. Revista de Investigación en Psicología, 7(1), 121-149. 